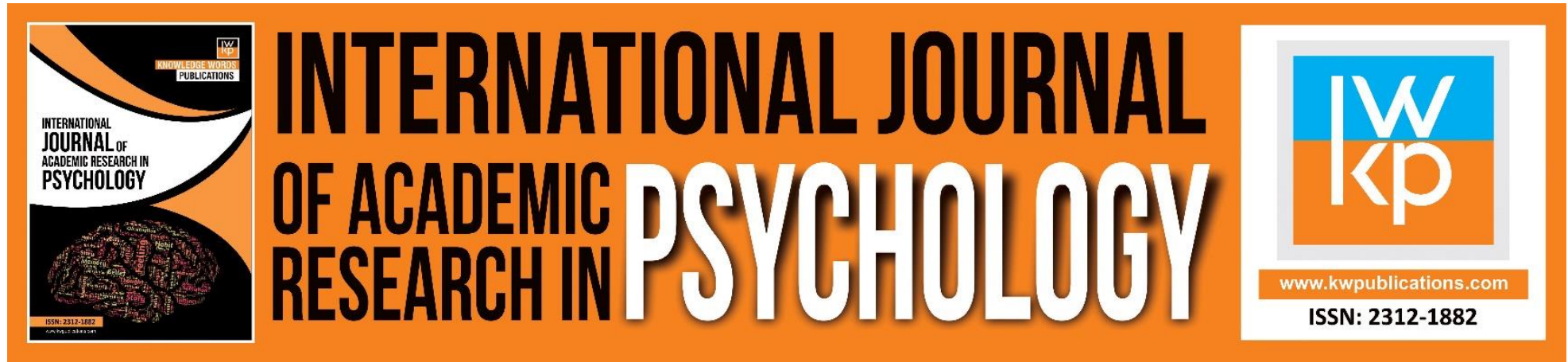

\title{
Impact of Motivation on the Psychological Wellbeing of Nurses in Enugu Metropolis
}

Chimezie Nwankwo, Chiamaka P. Okeke, O. J. Okeke

To Link this Article: http://dx.doi.org/10.46886/IJARP/v6-i1/4756

DOI: 10.46886/IJARP/v6-i1/4756

Received: 07 September 2019, Revised: 13 November 2019, Accepted: 26 November 2019

Published Online: 25 December 2019

In-Text Citation: (Nwankwo, et al., 2019)

To Cite this Article: Nwankwo, C., Okeke, C. P., \& Okeke, O. J. (2019). Impact of Motivation on the Psychological Wellbeing of Nurses in Enugu Metropolis. International Journal of Academic Research in Psychology, 6(1), 49-62.

\section{Copyright: (c) 2019 The Author(s)}

Published by Knowledge Words Publications (www.kwpublications.com)

This article is published under the Creative Commons Attribution (CC BY 4.0) license. Anyone may reproduce, distribute, translate and create derivative works of this article (for both commercial and non-commercial purposes), subject to full attribution to the original publication and authors. The full terms of this license may be seen at: http://creativecommons.org/licences/by/4.0/legalcode

Vol. 6, No. 1, 2019, Pg. 49 - 62

Full Terms \& Conditions of access and use can be found at https://kwpublications.com/pages/detail/publication-ethics 


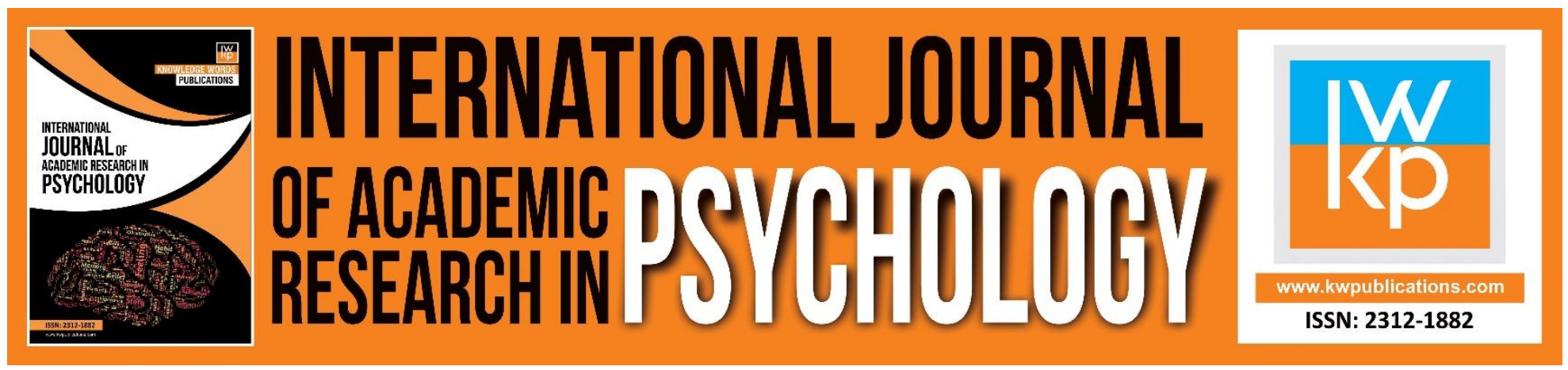

\title{
Impact of Motivation on the Psychological Wellbeing of Nurses in Enugu Metropolis
}

\author{
Chimezie Nwankwo (Ph.D), Chiamaka P. Okeke \\ Department of Psychology, Ebonyi State University, Abakaliki
}

\author{
O. J. Okeke (Ph.D) \\ Department of Chemistry Education, School of Science Education, \\ Enugu State College of Education (Technical) Enugu, In Affiliation to Nnamdi Azikiwe University \\ Akwa
}

\begin{abstract}
This study examined the impact of Motivation on the psychological wellbeing among Nurses. The design of the study used is Cohort. The area of the study is Enugu Metropolis. The population of the study is Two hundred and fifty (250) Nurses. The sample and sampling technique used are two hundred and fifty purposively selected. Two instruments were used to collect data. The instruments are Work extrinsic and intrinsic motivations and Warwick Edinburgh Mental Wellbeing scales that were adopted that indicated responses from the two hundred and fifty (250) Nurses. The instruments were validated by three experts, two from measurements and evaluation and one from psychology education. ANOVA was used to analyze responses from participants. Results show that motivation predicted psychological wellbeing among Nurses. Result indicated that motivation predicted psychological wellbeing with $(\beta=0.18, t=2.74)$. This clearly does not agree with the hypothesis that motivation will not significantly predict psychological wellbeing among Nurses. Hence the hypothesis which stated that motivation will not statistically significantly predict psychological wellbeing among Nurses was not confirmed. The study recommends that Nurses should be highly motivated in order to maintain stable psychological wellbeing.
\end{abstract}

Keywords: Motivation, Psychological, Wellbeing, Nurses.

\section{Introduction}

The psychological well-being has progressed rapidly since the emergence of the field over five decades ago. As recent surveys show psychologists and other social scientists have taken huge steps in their understanding of the factors influencing psychological/ subjective well-being. A person's selfreport of their psychological wellbeing are becoming a focus of intense debate in public policy and in economics, and improving the wellbeing of the population is emerging as a key societal aspiration. Psychological well-being is the subjective term that means different meanings to different people. Psychological well-being resides within the experience of the individual (Campbell, Converse, and 
INTERNATIONAL JOURNAL OF ACADEMIC RESEARCH IN PSYCHOLOGY

Vol. 6, No. 1, 2019, E-ISSN: 2312-1882 @ 2019 KWP

Rodgers, 1976). It is a person's evaluative reaction to his or her life either in terms of life satisfaction (Cognitive evaluation) or affective balance or the extent to which the level of positive effect outweighs the level of negative effect in someone's life (Andrew and Withey, 1976; Campbell et al.,1976; Diener, 1984).

According to Longman Dictionary of Contemporary English (2005) psychological well-being is a positive state of physical, mental and social well-being. It is not merely the absence of disease or infirmity. Motivation at work is found to be closely linked with job satisfaction and psychological wellbeing. People are motivated to behave in ways that have made them happy in the past and avoid behaviours which have led to them being sad (Nesse, 1989). Nesse (1989) suggest that from an evolutionary point of view, it is most useful for a person to conserve energy when the outcome is unlikely to be a good one but to use all energy stores when the effort will result in good consequences.

Motivation concerns what moves people to act, think, and develop. The central focus of motivation research is therefore on the conditions and processes that facilitate persistence, performance, healthy development, and vitality in human endeavors. Although, clearly, motivational processes can be studied in terms of underlying mechanisms in people's brains and physiology, the vast amount of variance in human motivation is not a function of the more proximal socio-cultural conditions in which actors find them. These social conditions and processes influence not only what people do but also how they feel while acting and as a consequence of acting. Most theories of human motivation have therefore focused on the effects of social environments, including the rewards, incentives, and relationship inherent in them, to better understand what activates and sustains effective functioning, not only because that is where variation is mostly readily observed but also because it is the most practical focus for interventions. In doing so, most theories have treated motivation as a unitary concept that varies primary in amount (Bandura, 1996; Baumeister and Vohs, 2007). They have assumed that more motivation, however catalyzed, will yield greater achievement and more successful functioning. Self-determination theory (SDT; Deci and Ryan, 2000; Ryan and Deci, 2000), in contrast, has maintained that there are different types of motivation, specifically, autonomous, controlled motivation and that this type of motivation is generally more important than the amount in predicting life's important outcomes.

Work motivation comprises of two important types of motivators, which could be classified as intrinsic or extrinsic. Intrinsic motivators include achievement, recognition, challenging work, increased responsibility, advancement and enjoyment while intrinsic motivation is itself the outcome, the result of a work situation that people enjoy because they are in charge, because they have the opportunity to acquire new skills and abilities to match a different challenge, or because they are part of a successful team. Whereas, extrinsic motivators include pay; fringe benefit, promotion, housing allowance, medical allowance, and status are the factors of extrinsic to the job. In addition to concrete rewards, content of the job itself, recognition and feedback from coworkers, supervisor and customers and accomplishing goals that are challenging and meaningful are more effective extrinsic motivators.

To compete in today's world, more than ever before, government must not only hire the best available nurses but also find ways to enable them to be productive and effective. The most productive and effective nurses are highly motivated and presumably in good health. Such nurses work energetically, produce high-quality outcomes, and perform optimally. Unfortunately, health problems in the workplace are on the rise (Vezina et al., 2008), resulting in higher cost, not only for 
INTERNATIONAL JOURNAL OF ACADEMIC RESEARCH IN PSYCHOLOGY

Vol. 6, No. 1, 2019, E-ISSN: 2312-1882 @ 2019 KWP

organization like productivity losses, high turnover, and absenteeism rates, but also for individuals (for example psychological stress and lower qualities of life).

\section{Statement of Problem}

The performance of nurses has come under serious criticism. They have been accused of high level of inefficiency in the discharge of their duties by the general public. Poor infrastructure, inadequate logistics, laxity in the upholding of ethical conducts, low salaries and inadequate reward system are hallmarks of the Health sector in Nigeria. Inadequate motivation among the health workers has led to industrial actions most of the time resulting in the low level of public confidence and respect in the institution and had further negative multiplier effects of poor performance, low morale and lack of discipline in the service. The public hospital in Nigeria have a greater percentage of death rate and unreported malpractice incident because the nurses are being neglected most patients do not have the means to pursue cases of negligence and error by practitioners in the course of their treatment. Even though management has instituted a number of motivational packages for staff including annual rewards to boost staff performance, anecdotal evidence has revealed conflicting messages with regard to its effect. So the question is, how effective are these motivation packages to the psychological wellbeing of nurses in Enugu Metropolis? The study therefore looks at the effects of motivation on the psychological wellbeing of nurses in Enugu Metropolis.

\section{Objectives of the Study}

The objectives of the study are to know whether motivation will determine psychological wellbeing among Nurses in Enugu Metropolis.

\section{Research Question}

To what extent does motivation influence the psychological wellbeing among nurses in Enugu Metropolis?

\section{Hypothesis}

The hypothesis postulated and tested in the course of this study is thus:

$\mathrm{H}_{0}$ : Motivation has no significant impact on the psychological wellbeing of nurses in Enugu Metropolis

\section{Review of Related Literature \\ Motivation}

Motivation can be defined as a reason or reasons for acting or behaving in a particular way and a desire or willingness to do something. It can be considered a driving force; a psychological drive that compels or reinforces an action toward a desired goal. Motivation elicits, controls, and sustains certain goal directed behaviors. Motivation has been considered using approaches considered to be physiological, behavioral, cognitive, and social. Motivation is conceptually related to, but distinct from, emotion, and may be rooted a basic response to optimize well-being, minimize physical pain and maximize pleasure, or originate from specific physical needs such as eating, sleeping or resting. Motivation can be divided into two types: internal, or intrinsic motivation, and external, or extrinsic motivation.

Intrinsic motivation refers to motivation that is driven by an interest or enjoyment in the task itself, and exists within the individual rather than relying on any external pressure. Intrinsic motivation is based on taking pleasure in an activity rather than working towards an external reward. 
Employees who are intrinsically motivated are more likely to engage in the task willingly as well as work to improve their skills, which will increase their capabilities. Employees are likely to be intrinsically motivated if they attribute their educational results to factors under their own control, also known as autonomy, believe they have the skill that will allow them to be effective agents in reaching desired goals (i.e. the results are not determined by luck).

Extrinsic motivation refers to the performance of an activity in order to attain an outcome, which then contradicts intrinsic motivation. It is widely believed that motivation performs two functions. The first is often referred to as the energetic activation component of the motivation construct. The second is directed at a specific behavior and makes reference to the orientation directional component. Extrinsic motivation comes from outside of the individual. Common extrinsic motivations are rewards like money and grades, and threat of punishment. Competition is in general extrinsic because it encourages the performer to win and beat others, not simply to enjoy the intrinsic rewards of the activity. A crowd cheering on the individual and trophies are also extrinsic incentives.

\section{Psychological Wellbeing}

Psychological wellbeing: the operational definition of psychological wellbeing in the study appears as being all right and not all right. Researchers identify levels of psychological wellbeing by summing up the scores of respondents given to the 14 items in the Warwick Edinburgh Mental Wellbeing Scale. Shortly, those with higher score reveals that are psychologically fine more than others and vice versa. Psychological well-being is the subjective term that means different meanings to different people. Psychological well-being resides within the experience of the individual (Campbell, Converse, and Rodgers, 1976). It is person's evaluate reaction to his or her life either in terms of life satisfaction (Cognitive evaluation) or affective balance or the extent to which the level of positive affect outweighs the level of negative effect in someone's life (Andrew and Withey, 1976; Campbell et al.,1976; Diener, 1984). Along with contextual influences psychological capital shapes the perception of wellbeing.

Psychological well-being is considered as a balance between positive effect and negative effect. Positive well-being is an appraisal of the status of one's functioning and outcome along several distinct but interrelated dimension including global, mental and physical healthfulness. According to Longman Dictionary of Contemporary English (2005) psychological well-being is a positive state of physical, mental and social well-being. It is not merely the absence of disease or infirmity. Motivation at work is found to be closely linked with job satisfaction and psychological well-being. Work motivation is identified as an energizing, directing and sustaining force (Steers Porter, 1983). Similarly, it is believed that individuals have certain self-centered needs that governs their behaviors and that the organization can, by satisfying these needs, motivate the individual to contribute towards the achievement of organizational goals.

\section{Theoretical Review}

\section{Theories of Motivation}

Self-Determination Theory (SDT) (Decci \& Ryan, 2002)

This is a theory of motivation. It is concerned with supporting our natural or intrinsic tendencies to behave in effective and healthy ways. It is also concerned with the motivation behind choices people make without external influence and interference. The theory was initially developed by (Decci \& Ryan, 2002). SDT focuses on the degree to which an individual's behavior is self-motivated and selfdetermined. It is centered on the on the belief that human nature shows persistent positive features, 
that it repeatedly shows effort, agency and commitment in their lives. This theory states that people have three basic psychological needs to motivate the self to initiate behavior and specify nutriment that are essential for psychological health and well-being of an individual. These needs are said to be universal, inmate and psychological and they include: competence, relatedness and autonomy.

1. Competence: means the desire to control and master the environment and outcome. We want to know how things will turn

2. Relatedness: deals with the desire to "interact with, be connected to, and experience caring for other people". Our actions and daily activities involve other people and through this, we seek the feeling of belongingness.

3. Autonomy: concerns with the urge, to be causal agents and to act in harmony with our integrated self. Deci and Ryan, (2000) stated that to be autonomous does not mean to be independent. It means having a sense of free will when doing something or acting out of our own interests and values.

Deci and Ryan (2000) claim that there are three essential elements of the theory: Humans are inherently proactive with their potential and mastering their inner force, such as drives and emotions,

1. Humans have an inherent tendency toward growth development and integrated functioning.

2. Optimal development and actions are inherent in humans but they don't happen automatically.

To actualize their inherent potential, they need nurturing from the social environment. If this happens there are positive consequences (e.g. wellbeing and growth) but if not, there are negative consequences. So SDT emphasizes humans' growth toward positive motivation; however, this is thwarted if their basic needs are not fulfilled.

This theory suggests that nurses will be motivated by their basic needs and it helps them behave in effective ways. Motivation is divided into two: Intrinsic motivation Ryan \& Deci (2000) define intrinsic motivation as "doing of an activity for its inherent satisfactions rather than for some separable consequences"

Simply put, an individual is intrinsically motivated to do something when he/she likes what they are doing. For instance, artists love painting; they paint for the sake of the activity itself, for the positive experience of performing not for the potential secondary gains that may arise from doing what they love.

\section{Two-Factor Theory (Hertzberg, 1959)}

The Two-Factor Theory of motivation otherwise known as dual-factor theory or motivationhygiene theory was developed by psychologist Frederick Herzberg in 1959. This theory states that there are certain factors in the work place that cause job satisfaction, while a separate set of factors cause dissatisfaction. Herzberg proposed a two-factor model of motivation, based on the notion that the presence of one set of job characteristics or incentives leads to worker satisfaction at work, while another separate set of job characteristic leads to dissatisfaction at work. Thus satisfaction and dissatisfaction are not on a continuum with one increasing as the other diminishes, but are independent phenomena. This theory suggests that to improve job attitudes and productivity, administrators must recognize and attend both sets of characteristics and not assume that an increase in satisfaction leads to decrease in dissatisfaction. Analyzing the responses of 203 accountants and 
engineers; who, were asked about their positive and negative feelings about their work, Herzberg found 2 factors that influence employee motivation and satisfaction.

1. Motivator factors: These are factors that lead to satisfaction and motivate employees to work harder. Examples might include enjoying your work, feeling recognized and career progression.

2. Hygiene factors: These are factors that do not give positive satisfaction or higher motivation, through dissatisfaction results from their absence. The term hygiene is used in the sense that these are maintenance factors. These are extrinsic to the work itself, and it can lead to dissatisfaction and a lack of motivation if they are absent. Examples include salary, company policies, benefits, relationships with managers and co-workers. These motivator factors increased nurse's satisfaction and motivation; the absence of these factors didn't necessarily cause dissatisfaction. Likewise, the presence of hygiene factors didn't appear to increase satisfaction and motivation but their absence caused an increase in dissatisfaction.

This theory states that while motivator and hygiene factors both influenced motivations. They appeared to work completely independently of each other and absence of both could cause dissatisfaction in work.

\section{Hierarchy of Needs (Maslow, 1943)}

The Hierarchy of Needs theory was coined by psychologist Abraham Maslow in his 1943 . The crux of the theory is that individuals' most basic needs must be met before they become motivated to achieve higher level needs.

Maslow's hierarchy of needs is often portrayed in the shape of a pyramid with the largest, most fundamental needs at the bottom and the need for self-actualization and self-transcendence at the top. The hierarchy is made up of 5 levels, but was later expanded and transcendence needs was added, (Maslow, 1970). The needs are as follows: physiological needs, safety needs, social belonging, esteem, self-actualization and self-transcendence.

1. Physiological needs: These needs must be met in order for a person to survive if these human requirements are not met the human body cannot function properly and will ultimately fail. Physiological- needs are thought to be the most important; they should be met first. They include food, water, sleep, clothing and shelter.

2. Safety needs: once a person's physiological needs are relatively satisfied, their safety needs take precedence and dominate their behavior. This includes personal and financial security and health and wellbeing. Which means that the person's surroundings are not threatening to them or their family? If the environment seems to be safe, then it means that there is a since of predictability or stability in the surroundings. Security could also include financial security so that there is no financial Uncertainty in the future. This could be achieved by creating a retirement package, securing job position, and insurance.

3. Social belonging: After physiological needs are fulfilled, the third level of human needs is interpersonal and involves feelings of belongingness. The need for friendships, intimacy and family. In the workplace, this means to feel as though they are a part of the group and included in the work. People have the urge to be accepted by others, especially the people they are around the most. 
INTERNATIONAL JOURNAL OF ACADEMIC RESEARCH IN PSYCHOLOGY

Vol. 6, No. 1, 2019, E-ISSN: 2312-1882 @ 2019 KWP

4. Esteem: The need to feel confident and be respected by others. The person must have a high image of them self and encompass self-respect. This level has two components: feelings of self-worth, and the need for respect from others. Low self-esteem or inferiority may result from imbalances during this level in the hierarchy. People with low self-esteem often need respect from others; they may feel the need to seek fame or glory. However, fame or glory will not help the person to build their self-esteem until they accept who they are internally. Psychological imbalances such as depression may hinder the person from obtaining a higher level of self-esteem or self-respect.

5. Self-actualization: this level of need refers to what a person's full potential is and the realization of that potential. The desire to achieve everything you possibly can and become the most that you can be. Someone being all they can be and they have met each of the previous stages. In this particular level, the person's talents are being completely utilized. Maslow believes that no one is ever completely self-actualized. People are always striving to be better and use their talents in new ways. This is important to motivation because a person must be; motivated to fulfill their needs and strive for the next level until they reach self-actualization.

6. Self-transcendence: In his later years, Maslow explored a further dimension of needs, while criticizing his own vision on self-actualization. The self only finds it actualization in giving itself to some higher goal outside oneself, in altruism and spirituality, which is essentially the desire to reach infinite, "Transcendence refers to the very highest and most inclusive or holistic levels of human consciousness, behaving and relating, as ends rather than means, to oneself, to significant others, to human beings in general, to other species, to nature, and to the cosmos". According to the hierarchy of needs, you must be in good health, safe and secure with meaningful relationships and confidence before you are able to be the most that you can be. These needs motivate humans to care for themselves and live a rich life. This theory explains that if nurses do not achieve basic needs and find out what motivate them in different stages so that they can be motivated to achieve higher level needs or achieve self-actualization and be rewarded accordingly.

\section{Expectancy Theory (Vroom, 1964)}

This theory was proposed by Vroom H. V. in 1964 proposes that people will choose how to behave depending on the outcomes they expect as a result of their behavior. In other words, we decide what to do base on what we expect the outcome to be. At work, it might be that we work longer hours because we expect a pay rise. This theory emphasizes the needs for organizations to relate rewards directly to performance and to ensure that the rewards provided are those rewards deserved and wanted by the recipients.

However, Expectancy Theory also suggests that the process by which we decide our behaviors is also influenced by how likely we perceive those rewards to be. In this instance, workers may be more likely to work harder if they had been promised a pay rise (and thus perceived that outcome as very likely) than if they had only assumed, they might get one (and perceived the outcome as possible but not likely)

Like many theories of motivation, the nature of the goal is often ignored. Motivation theory has the tendency to see what is going on within the actor, rather than focusing on the goal itself. In this case, the goal seeker is one who wants to show competence and, therefore, will choose those goals that seem relatively safe, with a high degree of expectancy that they can be done. There are three variables intrinsic 
INTERNATIONAL JOURNAL OF ACADEMIC RESEARCH IN PSYCHOLOGY

Vol. 6, No. 1, 2019, E-ISSN: 2312-1882 @ 2019 KWP

to expectancy. First, something is in it for the actor when the goal is finished. There is a "perceived outcome" in the goal itself, usually focused around showing competence and a feeling of accomplishment. Second, the job itself can be done with a minimum of frustrations. This remains one of the most common and important basic theories of motivation. Finally, one's ego will find some rest in the task. In other words, the task at hand will manifest one's capabilities and show everyone how competent he is.

\section{Expectancy Theory is Based on Three Elements}

1. Expectancy: the belief that your effort will result in your desired goal. This is based on your past experience, your self-confidence and how difficult you think the goal is to achieve.

2. Instrumentality: the belief that you will receive a reward if you meet performance expectations.

3. Valence: the value you place on the reward.

Therefore, according to Expectancy Theory, nurses are most motivated if they believe that they will receive a desired reward if they hit an achievable target. They are least motivated if they don't want the reward or they don't believe that their efforts will result in the reward.

\section{Empirical Review}

\section{Motivation and Psychological Wellbeing}

Gokce, (2014) studied the relationships between basic psychological needs, motivational regulations, self-esteem, subjective vitality, and social physique anxiety in physical education. One thousand and eighty two high school students aged between 14 and 19 [mean (M) = $15.89 \pm 0.95$ years] from six public high schools participated to the study. Students' basic psychological needs: motivational regulations, subjective vitality and self-esteem served as positive indicators, while social physique anxiety was a negative indicator of psychological well-being. Structural equation modeling results revealed that students' motivational regulations mediated the relationship between basic psychological needs and psychological well-being. Intrinsic motivation negatively predicted social physique anxiety and positively predicted subjective vitality. A motivation positively predicted social physique anxiety and negatively predicted subjective vitality. Identified regulation and external regulation positively predicted subjective vitality. Results supported the tenets of Self Determination Theory (SDT) and suggested that satisfying adolescents' basic psychological needs in physical education will promote their psychological well-being.

Persefoni, Nick \& Dimitris (2010) conducted a study to investigate how medical and nursing staff of the Nicosia General Hospital is affected by specific motivation factors, and the association between job satisfaction and motivation. Furthermore, to determine the motivational drive of socio-demographic and job related factors in terms of improving work performance. He used instruments developed for measuring motivation based on Maslow's and Herzberg's theories was used in the present study. It consists of 19 items which are grouped under four distinct motivational factors. The job attributes factor encompasses 7 items: authority, goals, creativity opportunities, clear duties, job control, skill exploitation and decision-making. The remuneration factor encompasses 4 items: salary, environment, retirement/pension and absenteeism. The co-workers factor encompasses 5 items: teamwork, job pride, appreciation, I supervisor and fairness. The achievements factor encompasses 3 items: job meaningfulness, earned respect and interpersonal relationships. Two categories of health care professionals, medical doctors and dentists $(N=67)$ and nurses $(N=219)$ participated and motivation and job satisfaction were compared across socio-demographic and occupational variables. The survey 
revealed that achievements were ranked first among the four motivators, followed by remuneration, co-workers and job attributes. The factor remuneration revealed statistically significant differences according to gender, and hospital sector, with female doctors and nurses and accident and emergency $(A+E)$ outpatient doctors reporting greater mean scores $(p<0,005)$, The medical staff showed statistically significantly lower job satisfaction compared to the nursing staff, Surgical sector nurses and $>55$ years of age reported higher job satisfaction when compared to the other groups. The results are in agreement with the literature which focuses attention to management approaches employing' both monetary and non-monetary incentives to motivate health care professionals Health care professionals tend to be motivated more by intrinsic factors, implying that this should be a target for effective employee motivation, Strategies based on the survey's results to enhance employee motivation are suggested.

\section{Methodology}

\section{Participants}

Participants in this study were 250 nurses, comprising 42 males and 208 females. Purposive sampling techniques (also known as judgment, selective or subjective sampling) was used to draw participants from five health institutions in Enugu Metropolis in Enugu State. The participants were nurses of Federal Neuropsychiatric hospital, New Haven, Uwani Cottage Health center Uwani, Poly SubDistrict hospital Asata, Federal Orthopedic hospital, and Enugu State University Teaching Hospital, Parklane. Their age ranges from 20-60 years with a mean age of 46.33 .

\begin{tabular}{|l|l|}
\hline Hospitals & Numbers \\
\hline Federal Neuropsychiatric hospital & 59 \\
\hline Uwani cottage Health center & 29 \\
\hline Poly Sub-District hospital, Asata & 35 \\
\hline Federal Orthopedic Hospital & 62 \\
\hline $\begin{array}{l}\text { Enugu State University Teaching Hospital } \\
\text { Parklane }\end{array}$ & 61 \\
\hline
\end{tabular}

\section{Instruments}

Two instruments were used in this study

The Warwick Edinburgh Mental Well-being Scale, developed and validated by Tennant, Hiller. Fishwick, Platt, Joseph, Welch, Parkinson, Seeker, Stewart-Brown (2007), it was used to access students with the age of 16years and above in the UK measuring aspects of mental health involving surveys in both student and general population samples, and focus groups. The scale has 4 items is scored by summing the response to each item answered on a 1 to 5 likert scale with the response as- None of the time, Rarely, Some of the time, Often and All of the time. The minimum scale score is 14 and the maximum is 70 . The scale has full scale reliability of .83 obtained using Cronbach's alpha coefficient of .\&9. 1 gave the questionnaires to six lecturers who face validated the questionnaires and rated the cronbach alpha high. The Work Extrinsic and Intrinsic Motivation Scale (WEIMS) is an 18-item scale designed to measure work motivation. It was developed and validated by Tremblay, Blanchard, Taylor \& Pelletier (2009). WEIMS was used to examine the influence of work self-determined as opposed to non-selfdetermined motivation. A score for W-SDM (Work-Self Determined Motivation) can be generated by summing the means of each of the three self-determined subscales (i.e., Intrinsic Motivation, Integrated Regulation, and Identified Regulation), which some of the items are; Because I derive 
INTERNATIONAL JOURNAL OF ACADEMIC RESEARCH IN PSYCHOLOGY

Vol. 6, No. 1, 2019, E-ISSN: 2312-1882 @ 2019 KWP

much pleasure from learning new things, Because it is part of the way in which I have chosen to live my life, Because this is the type of work I chose to do to attain s. certain lifestyle.

Similarly, a score for W-NSDM (Work-Non Self-determination Motivation) can be obtained by summing the means of the three non-self-determined subscales (i.e., Introjected Regulation, External Regulation, and A motivation), which some of the items include: I don't know why, we are provided with unrealistic working conditions, For the income it provides me, Because I want to be a "winner" in life. Internal consistency values of .87 and, 72 were obtained for work self-determined and non-self-determined motivation, respectively. WEIMS would respectively load on six separate latent constructs (i.e., three items per factor). I gave the questionnaires to six lecturers who face validated the questionnaires and rated the cronbach alpha high.

\section{Procedures}

The questionnaires were administered to 250 nurses from five hospitals in Enugu metropolis; the questionnaires were administered to different hospitals on different days. The researcher sought permission from the head of nursing services in the different health institution to administer the questionnaires. The researcher rendered lots of thanks to the participants. Design/Statistics

The study employed a cross-sectional design. The statistics used in this is one way Analysis of Variance (ANOVA).

Out of the 250 pies 245 was collected representing a ratio of 98\%, 10 copies were discarded due to improper filling leaving a total number of 235 that were used for analysis on this study, 195 females and 45 males.

\section{Summary of Main Finding}

Table 1: Means, standard deviations, and correlations for age, and motivation on psychological wellbeing ,

\begin{tabular}{|c|c|c|c|c|c|c|}
\hline $\mathrm{S} / \mathrm{N}$ & Va & & $M$ & $S D$ & Motivation & Psy- \\
\hline 1 & Motivation & 63.45 & & .09 & & \\
\hline 2 & Psy-well being & 45.84 & & -.02 & & $.18^{* *}$ \\
\hline
\end{tabular}

Result of correlation table show that psychological wellbeing was positively significantly related to motivation $(r=.18, p<.01)$; but negatively non-significantly related to age $(r=-.03, p>.05)$ and negatively non-significantly related to motivation $(r=-.09, p>.05)$. 
INTERNATIONAL JOURNAL OF ACADEMIC RESEARCH IN PSYCHOLOGY

Vol. 6, No. 1, 2019, E-ISSN: 2312-1882 @ 2019 KWP

Table 2: Showing the prediction of 'psychological well being' from control variable-age, and motivation

$R$

$\mathrm{R} 2$

R2A B $\operatorname{Beta}(\mathrm{p}) \quad \mathrm{T}$

Model 1

$\begin{array}{lllllll}\text { Age } & .031 & 001 & .001 & -.04 & -.03 & -.48\end{array}$

Model2

Motivation

$\begin{array}{llll}.181 * * & .033 * * & .031 * * & .11\end{array}$

$.18 \quad 2.74 * *$

Table 2 result indicated that the demographic (age) did not significantly predict psychological wellbeing of nurses ( $\mathrm{P}--.03, \mathrm{t}--.48$ ) But motivation entered in model three of the equation was a significant positive predictor of psychological wellbeing of nurses $((3=.18, t=2.74, p<01)$. It however accounted for $31 \%$ variance in the explanation of psychological wellbeing of nurses (R2A $=.031, \mathrm{p}<.01$ ). Thus increase in motivation increases psychological wellbeing of nurses.

\section{Discussion}

The result of the study revealed that motivation statistically significantly predicted Nurses psychological wellbeing. This simply means that psychological wellbeing is a complex combination of a person's physical, mental, emotional and social health. The impact of the psychological wellbeing is very high on the motivational level of the nurses because of better work relationships, work life balance, job security and salary and other benefits which keep the employee satisfied and contented and thus it return helps the employee to perform better, more productivity, less absenteeism, low turnover, emotional stable, physical healthy, mentally at peace and also establish better understanding with others. So the more the nurses are psychological balance, there would be more contribution to the organization. Emotional demands from nursing professionals can act as challenges which promote motivation and psychological wellbeing. The above result is in line with earlier studies which suggest that higher the motivation to work, lesser will be the overall psychological wellbeing, as recognition in work place is found to be effective in determining one's psychological well-being (Ryan \& Deci, 2000).

\section{Conclusion}

Based on the finding of the study the researcher hereby concludes that there is significant impact of motivation on the psychological wellbeing of nurses $n$ Enugu Metropolis. The Psychological wellbeing of the Nurses has significant impact on the motivation level and it facilitates in achieving the business objectives of the health sector. This implies that the motivation of nurses is a gate way to Nurses psychological wellbeing. The result of the present study confirms that previous research shows that motivational regulations mediated the relationship between basic psychological needs and psychological well-being.

\section{Recommendations}

Based on the findings of this study, the following are the recommendations

1. Other studies should be done on the motivation and gender as predictors of psychological wellbeing among Nurses using a larger sample, and on other factors that can have influence on psychological wellbeing should be examined, such as emotions, healthy foods, etc. 
INTERNATIONAL JOURNAL OF ACADEMIC RESEARCH IN PSYCHOLOGY

Vol. 6, No. 1, 2019, E-ISSN: 2312-1882 @ 2019 KWP

2. In future research, open-ended questions or interviews could be supplemented in order to create a richer qualitative piece to the research and better understand what motivates nurses at a particular time

3. Government should highly motivate the Nurses by Reduce the nurse labor expense without sacrificing quality of care, better work relationships, work life balance, job security and salary and other benefits which keep the Nurses satisfied and contented and thus in return helps the Nurses to perform better, more productivity, less absenteeism, low turnover, emotional stable, physical healthy, mentally at peace and also establish better understanding with others.

\section{References}

Bandura, A. (1996). Self-efficacy: The exercise of control. New York: Freeman.

Baumeister, R. F., \& Vohs, K. D. (2007).Self-regulation, ego depletion, and motivation. Social and Personality Psychology. Compass, 1, 1-14.

Campbell, A., Converse, P. E., \& Rodgers W. L. (1976).The Quality of American Life: Perceptions, Evaluations and Satisfactions. New York: Russell Sage Foundation.

Chukwuneke, F. N., Ezeonu, C. T., Onyire, B. N., Ezeonu, P. O., Ifebunandu, N., and Umeora, M. C. (2012). Health Seeking Behaviour and Access to Health Care Facilities at the Primary Level in Nigeria: Our Experience. Ebonyi Medical Journal, 11, 51-57.

Deci, E. L., \& Ryan, R. M. (2000). The "what" and "why" of goal pursuits: Human needs and the selfdetermination of behavior. Psychological Inquiry, 11, 227-268.

Diener, E. (1984). Subjective Well-Being. Psychological Bulletin, 95, (3).

Dewani, V. (2013) "Motivation".slideshare. Retrieved 22 March2017.

Gokce, E. I. (2014). Psychological well-being and motivation in a Turkish physical education context. Journal of Educational Psychology in Practice theory, research and practice in educational psychology, 30(4).

Herzberg, F., Mausner, B., \& Snyderman, B. B. (1959). The Motivation to Work (2nd ed.). New York: John Wiley.

Hull, C. L. (1943). Principles of behavior: An Introduction to Behavior Theory. New York: AppletonCentury-Crofts

Marinak, B. A., \& Gambrell, L. B. (2008). Intrinsic Motivation and Rewards: What Sustains Young Children's Engagement with Text?

Maslow, A. H. (1943). "A theory of human motivation". Psychological Review. 50 (4): 370-96. Maslow, A. H. (1970). Motivation and personality. New York: Harper \& Row. McClelland, D. C. (1955). Studies on Motivation. Appleton-Century, New York.

Nesse, R. M. (1989). Pain disorder. An evolutionary view. Psychiatry Ann. 75, 478-483.

Persefoni, L., Nick, K., \& Dimitris, N. (2010). Motivation and job satisfaction among medical and nursing staff in a Cyprus public general hospital. Human Resources for Health, 8 (26)

Ryan, R. M., \& Deci, E. L. (2001). Self-determination theory and the facilitation of intrinsic motivation, social development, and well-being. American Psychologist, 55, 68 -78.

Ryan, R., Edward, L. D. (2000). "Intrinsic and Extrinsic Motivations: Classic Definitions and New Directions". Contemporary Educational Psychology. 25 (1): 54-67

Ryan, R. M., \& Deci, E. L. (2002). An overview of Self-determination Theory: An organismicdialectical perspective. In E. L. Deci \& R. M. Ryan (Eds.), Handbook of self-determination research. 3-33. Rochester, NY: The University of Rochester Press. 
Vezina, M., Bourbonnais, R., Mare'riafM, A., \& Arcand, R. (2008). Stressau travail et sante mentale chez les adultesquebecois. Enquete sur lasante dans les collectivites canadiennes (cycle 1.2), Quebec, Canada:Institut de la Statistique du Quebec.

Vroom, V. H. (1964). Work and motivation. San Francisco, CA: Jossey-Bass

Wegner, M., Schwarzer, R., Jerusalem, M. (1981/1993). Generalized Self-efficacy Scale.In Schwarzer, R. (Ed.), Measurement of perceived self-efficacy. Psychometric scales for cross cultural research (pp. 1-25). Berlin

Wilson, T., \& Lassiter, G. (1982). Increasing intrinsic interest with superfluous extrinsic constraints.Jowrna/ of Personality and Social Psychology. 42. 811-819. 10 